\title{
Polycomb group protein Bmi1 is required for the neuronal differentiation of mouse induced pluripotent stem cells
}

\author{
WEI SHAN ${ }^{1}$, LIPING ZHOU ${ }^{1}$, LIZHEN LIU $^{2}$, DEJU LIN $^{1}$ and QIN YU $^{1}$ \\ ${ }^{1}$ College of Life Science, Zhejiang Chinese Medical University, Hangzhou, Zheijiang 310053; \\ ${ }^{2}$ Bone Marrow Transplantation Center, The First Affiliated Hospital, \\ Zhejiang University School of Medicine, Hangzhou, Hangzhou Zheijiang 310003, P.R. China
}

Received June 25, 2018; Accepted March 18, 2021

DOI: $10.3892 /$ etm.2021.10051

\begin{abstract}
Induced pluripotent stem cells (iPSCs) reprogrammed by somatic cells may be used as a potentially novel treatment regimen in stem cell regenerative medicine, particularly in the central nervous system (CNS). In the present study, iPSCs were generated using mouse embryonic fibroblasts by ectopic overexpression of Sox-2, Oct-3/4, Klf-4 and c-Myc, and cultured under the same conditions as that used for embryonic stem cells. The neuronal differentiation capacity of mouse iPSCs was examined, and the involvement of the formation of embryoid bodies was assessed. The results suggested that after 15 days of neuronal inducement, Nestin, Vimentin and Glast protein expression levels were significantly increased in the mouse iPSC-derived cells. Additionally, Bmil, which is selectively expressed in differentiated postnatal adult stem cells. such as hematopoietic stem cells and neural stem cells, was required for establishment of the neuronal differentiation of mouse iPSCs. In order to assess the effects of Bmi1 in neuronal differentiation, Bmil expression levels were inhibited with the small molecule PTC-209. The results showed that inhibition of Bmil expression reduced the expression of neuronal markers, such as Nestin, compared with the controls. These results suggested that mouse iPSCs can be induced to achieve neuronal differentiation. More interestingly, Bmi1 was required during the neuronal differentiation of mouse iPSCs.
\end{abstract}

\section{Introduction}

Neuronal loss frequently results in neurological injury and underlies several neurological diseases $(1,2)$. Treatments aimed to replace lost neurons have shown significant success, both in studies and when used clinically (3-5). Induced

Correspondence to: Professor Qin Yu, College of Life Science, Zhejiang Chinese Medical University, 548 Binwen Road, Hangzhou, Zhejiang 310053, P.R. China

E-mail: qinyu3587@126.com

Key words: mouse induced pluripotent stem cells, neuronal differentiation, Bmil, neural stem cell pluripotent stem cells (iPSCs), which are reprogrammed somatic cells, exhibit similar functional abilities to that of embryonic stem cells (ESCs) with regard to self-renewal ability and differentiation capacity. They show great promise for the development of clinical cell-based applications (6-8). Recently, trials on ESCs or iPSCs derived from neural cells have been assessed as a treatment for Parkinson's disease and macular degeneration $(9,10)$. However, the generation of a sufficient number of functional neural cells from pluripotent stem cells (PSCs) remains challenging, owing to certain hurdles, including unclear neural differentiation mechanisms and low differentiation efficiency (11). Therefore, an effective method for production of functional neural cell types is required. In addition, certain obstacles remain, such as the effects of the external regulatory environment, as well as the specific molecular mechanisms involved with regard to neural differentiation of PSCs.

To date, there are three major established regimens used for differentiation of PSCs into neural precursor cells: Promoting the direct neural differentiation of PSCs; co-culture of PSCs with stromal cells, such as MS5 and PA6; or use of a multistep procedure that includes the formation of embryoid bodies (EBs) (12). Based on the use of a suspension culture or the hanging drop method in vitro, the structure of EBs formed exhibit definitive aspects of early embryogenesis with lineage specific regions, similar to what is observed in vivo (7). Retinoic acid (RA), one of the most significant morphogens, is required for neural differentiation of mouse ESCs (13). In the present study, the neural differentiation protocol that was involved in the formation of EBs was established. Through the combination of RA with N2B27 medium, cytokines were supplemented to promote neuronal differentiation (3). Polycomb group proteins $(\mathrm{PcG})$ are primarily described in relation to their roles in Drosophila, in which embryonic development is regulated through the repression of homeotic genes $(6,14)$. Bmil, a member of the PcG family of proteins, is required for the maintenance of self-renewing adult neural stem cells (NSCs) in vivo and in vitro $(15,16)$. Bmil knockout mice experiments showed that it was essential for postnatal self-renewal of NSCs by regulating the cell-cycle inhibitors, p16/p19 (17). Additionally, short hairpin RNA-mediated knockdown of Bmil revealed that the p21-Rb pathway is crucial for self-renewal of NSCs during embryonic development (18). Together, these previous 
studies highlight the essential role of Bmil in maintaining the biological function of NSCs. To date, the role of Bmi1 in neuronal differentiation of PSCs has not been determined, to the best of our knowledge. In the present study, whether Bmi1 could regulate the neuronal differentiation of mouse iPSCs via the formation of EBs was assessed. The aim of the present study was to establish an ex vivo detection paradigm to explore the neuronal development capacity of PSCs.

\section{Materials and methods}

Cell culture. Mouse embryonic fibroblasts (MEFs) were separated from the embryos of female mice after 14.5 days of pregnancy. The specific procedure of deriving MEFs was as follows: The ICR mouse was sacrificed by cervical spondylolisthesis, and the abdomen was saturated with $70 \%$ ethanol. Sterilized instruments were used to cut the peritoneal wall and expose the uterine horns, which were removed and placed in a clean disposable Petri dish in PBS. The embryos were obtained and minced. The minced tissue was trypsinized and incubated in DMEM (Invitrogen; Thermo Fisher Scientific, Inc.) supplemented with $10 \%$ of FBS (Gibco; Thermo Fisher Scientific, Inc.), $1 \%$ nonessential amino acids (Invitrogen; Thermo Fisher Scientific, Inc.), 1\% L-glutamine (Invitrogen; Thermo Fisher Scientific, Inc.) and penicillin/streptomycin (Beijing Solarbio Science \& Technology Co., Ltd.) to grow the MEFs.

293 T cells were kindly provided by the Stem Cell Bank, Chinese Academy of Sciences (Serial no. GNHu17) and cultured in DMEM high glucose (Invitrogen; Thermo Fisher Scientific, Inc.) supplemented with $10 \%$ FBS and penicillin/streptomycin. All animal experiments were performed in accordance with the guidelines described in the Institutional Animal Care Committee of Zhejiang Chinese Medical University. The present study was approved by the Laboratory Animal Management and Welfare Ethical Review Committee (approval no. ZSLL-2017-181).

Retrovirus production and infection, and generation of mouse iPSCs. Moloney-based retroviral vectors (pMXs) containing the human genes encoding c-Myc, Klf4, Sox 2 and Oct3/4 (all established cell-reprogramming factors) (19) were obtained from Addgene, Inc. Each plasmid was co-transfected into 293 T cells with the packaging plasmids pCMV-GP and pCMV-G (kindly provided by Professor Jing-Kuan Yee, Department of Diabetes and Metabolic Diseases Research, Beckman Research Institute, City of Hope National Medical Center) by co-precipitation of calcium phosphate. Specifically, $15 \mu \mathrm{g}$ retroviral vector for Oct3/4, Sox 2, K1f4 and c-Myc, $15 \mu \mathrm{g}$ pCMV-GP and $4 \mu \mathrm{g}$ pCMV-G was transfected. After 48 and $72 \mathrm{~h}$, retrovirus-containing supernatants derived from $293 \mathrm{~T}$ cultures were filtered using a $0.45 \mu \mathrm{m}$ filter (EMD Millipore) and $4 \mu \mathrm{g} / \mathrm{ml}$ polybrene was added (Sigma-Aldrich; Merck KGaA). Subsequently, the MEFs were treated with the virus/polybrene mixture twice for 8-10 h, when the cells had reached $60-70 \%$ confluence. Next, the media was replaced with DMEM/F12 (Invitrogen; Thermo Fisher Scientific, Inc.) supplemented with 15\% FBS (Gibco; Thermo Fisher Scientific, Inc.), $1 \%$ non-essential amino acids (Invitrogen; Thermo Fisher Scientific, Inc.), $1 \%$ (Invitrogen; Thermo Fisher Scientific, Inc.), $0.1 \mathrm{mM}$ 2-mercaptoethanol (Sigma-Aldrich; Merck KGaA),
$1,000 \mathrm{U} / \mathrm{ml}$ leukemia inhibitor factor (Biolead) and penicillin/streptomycin (mouse ESC medium). Valproic acid (1 mM; Sigma-Aldrich; Merck KGaA) was added from days 3-8, and Vitamin C (25 $\mu \mathrm{g} / \mathrm{ml}$; Sigma-Aldrich; Merck KGaA) was added from days 2-12 or 14. After 12-14 days of infection, the well-defined colonies were screened out and expanded on the inactivated MEF feeder layers in mouse ESC medium for passaging. The inactivated MEF feeder layers were established via treating the MEFs for $2 \mathrm{~h}$ at $37^{\circ} \mathrm{C}$ using mitomycin $\mathrm{C}$ (7 $\mu \mathrm{g} / \mathrm{ml}$; Sigma-Aldrich; Merck KGaA).

Alkaline phosphatase (AP) staining and immunofluorescence analysis. AP staining was performed using an Alkaline Phosphatase staining kit (EMD Millipore). For immunofluorescence staining, cells were cultured in plates, and fixed and immunostained using established standard protocols $(1,20)$. After washing with immunostaining wash buffer, the cells were sealed with immune staining blocking buffer at room temperature for $60 \mathrm{~min}$, and stained with primary antibodies at appropriate dilutions for $90 \mathrm{~min}$ at room temperature. The following antibodies and dilutions were used: Anti-Oct3/4 (1 $\mu \mathrm{g} / \mathrm{ml}$; cat. no. ab19857; Abcam), anti-SSEA-1 (5 $\mu \mathrm{g} / \mathrm{ml}$; cat. no. ab16285; Abcam), anti- $\alpha$-Fetoprotein (1:50; cat. no. GTX30030; GeneTex), anti-Sox2 (1 $\mu \mathrm{g} / \mathrm{ml}$; cat. no. ab97959; Abcam), anti-Smooth Muscle Actin (SMA; 1:300; cat. no. ab124964; Abcam), anti- $\beta$ III Tubulin ( $1 \mu \mathrm{g} / \mathrm{ml}$; cat. no. ab68193; Abcam), anti-Vimentin (1:300; cat. no. ab92547; Abcam), anti-Nestin (1 $\mu \mathrm{g} / \mathrm{ml}$; cat. no. ab68193; Abcam), anti-Vimentin (1:300; cat. no. NBP1-02419; Novus Biologicals LLC), Subsequently, cells were stained with secondary antibodies (1:1,000; Alexa Fluor 488 labeled Goat anti-Rabbit IgG; cat. no. ab150077; Abcam or 1:1,000; Alexa Fluor 555 labeled Donkey anti-Rabbit IgG; cat. no. A-31572; Thermo Fisher Scientific, Inc.) for 30-60 min at room temperature. To stain the nuclei, $1 \mu \mathrm{g} / \mathrm{ml}$ DAPI was used for $10 \mathrm{~min}$ at room temperature. Cells were imaged at x100 magnification using an inverted fluorescence microscope (Nikon Corporation). All of the immune reagents including the Fixative Solution, Immunol Staining Wash Buffer, Primary Antibody Dilution Buffer and Secondary Antibody Dilution Buffer were purchased from Hang Zhou Da Wen Biotechnology Co., Ltd.

Formation of EBs. For formation of EBs, mouse iPSCs were suspended in the mouse ESC medium without $\mathrm{LiF}$ and cultured in $10 \mathrm{~mm}$ culture dishes at $37^{\circ} \mathrm{C}$ for $40 \mathrm{~min}$ to remove the $\mathrm{MEF}$ layers. Then, $2 \times 10^{5}$ single mouse iPSCs were cultured in $60 \mathrm{~mm}$ petri dishes with mouse ESC medium and without LiF (termed EB medium). After the first and second day, petri dishes were gently shaken to prevent the adherence of the cells. After 8 days, EBs had formed and images were taken at x40 magnification using an inverted light microscope (Nikon Corporation).

Neural differentiation ability of mouse iPSCs. First, mouse iPSCs were suspended for 3 days upon the formation of EBs (days 0-3). Then, EBs were treated with $1 \mu \mathrm{M}$ all-trans RA (Sigma-Aldrich; Merck KGaA) for 4 days (days 3-7). EBs were plated onto $0.1 \%$ gelatin-coated dishes in N2B27 medium supplemented with $10 \mu \mathrm{g} / \mathrm{ml}$ basic fibroblast growth factor (bFGF) (PeproTech, Inc.), $10 \mu \mathrm{g} / \mathrm{ml}$ epidermal growth factor (EGF) (PeproTech, Inc.) and $1 \mu \mathrm{M} / \mathrm{ml}$ PTC-209 
Table I. Sequences of the primers used for PCR.

\begin{tabular}{ll}
\hline Gene & \multicolumn{1}{c}{ Sequence, 5'-3' $^{\prime}$} \\
\hline Oct3/4 & \\
Forward & CCCCAGGGCCCCATTTTGGTACC \\
Reverse & CCCTTTTCTGGAGACTAAATAAA \\
SOX2 & \\
Forward & GGCACCCCTGGCATGGCTCTTGGCTC \\
Reverse & CCCTTTTCTGGAGACTAAATAAA \\
c-Myc & \\
Forward & CAACAACCGAAAATGCACCAGCCCCAG \\
Reverse & CCCTTTTTCTGAGACTAAATAAA \\
Klf4 & \\
Forward & ACGATCGTGGCCCCGGAAAAGGACC \\
Reverse & CCCTTTTCTGGAGACTAAATAAA \\
Nat1 & \\
Forward & ATTCTTCGTTGTCAAGCCGCCAAAGTGGAG \\
Reverse & AGTTGTTTGCTGCGGAGTTGTCATCTCGTC \\
\hline
\end{tabular}

(Selleck-chem) for 6-7 days (days 7-15). The media was replaced every other day. The N2B27 medium was a 1:1 mixture of DMEM/F12 supplemented with N2 (Invitrogen; Thermo Fisher Scientific, Inc.) and neurobasal media added, and supplemented with B27 (Invitrogen; Thermo Fisher Scientific, Inc.). Images were obtained at x100 magnification using an inverted light microscope (Nikon Corporation).

Flow cytometry analysis. The general flow cytometry analysis protocols were performed as follows: The cells were centrifuged for $5 \mathrm{~min}$ at $400 \mathrm{x} \mathrm{g}$ and $10^{\circ} \mathrm{C}$. Single cell suspensions were obtained in a solution consisting of PBS supplemented with $2 \% \mathrm{FBS}$, and then re-suspended in $200 \mu \mathrm{l} 4 \%$ paraformaldehyde and fixed at room temperature for $10 \mathrm{~min}$. The cells were permeabilized using $100 \mu \mathrm{l}$ PBS with $0.1 \%$ Triton $\mathrm{X}-100$ (cat. no. ST797; Beyotime Institute of Biotechnology) for $20 \mathrm{~min}$ at $4^{\circ} \mathrm{C}$. The primary antibodies were added and cells were incubated at $4^{\circ} \mathrm{C}$ for $30 \mathrm{~min}$, and then subsequently, cells were treated with the corresponding secondary antibody at $4^{\circ} \mathrm{C}$ for $30 \mathrm{~min}$. Next, flow cytometry was performed using a BD Fortessa (Becton-Dickinson and Company). Analysis of the flow data was performed using FlowJo version 10 (FlowJo, LLC). The primary antibodies used were mouse anti-Nestin polyclonal antibody (1:200; Abcam; cat. no. ab1642) and mouse anti-GFAP polyclonal antibody (1:200; Abcam; cat. no. ab10062). The secondary antibody used was an anti-mouse IgG H\&L-AlexaFluor 488 (1:1,000; Abcam; cat. no. ab150105).

Reverse transcription-quantitative $(R T-q) P C R$. Total RNA was extracted from untransfected MEFs, as well as MEFs transfected with retroviral particles expressing Oct3/4, SOX-2, c-Myc and Klf4 using TRIzol ${ }^{\circledR}$ reagent (Invitrogen; Thermo Fisher Scientific, Inc.) according to the manufacturer's protocol. cDNA was synthesized from the RNA using the PrimeScript $^{\mathrm{TM}}$ RT reagent kit (Takara Bio, Inc.) according to the manufacturer's protocol. PCR was performed using
Table II. Sequences of the primers used for quantitative PCR.

\begin{tabular}{ll}
\hline Gene & \multicolumn{1}{c}{ Sequence, 5'-3' } \\
\hline $\begin{array}{l}\text { Oct3/4 } \\
\text { Forward } \\
\text { Reverse } \\
\text { SOX2 }\end{array}$ & AGAGGATCACCTTGGGGTACA \\
Forward & \\
Reverse & GCGGAGTGGAAACTTTTGTCC \\
c-Myc & CGGGAAGCGTGTACTTATCCTT \\
Forward & \\
Reverse & CCGCTCAAGTTGCTCGAAAAG \\
Nanog & TCTCCTTGTAAGACATTGCTGAC \\
Forward & \\
Reverse & TCTTCCTGGTCCCCACAGTTT \\
Klf4 & GCAAGAATAGTTCTCGGGATGAA \\
Forward & \\
Reverse & CCAGACCAGATGCAGTCACA \\
GAPDH & GCAGGTGTGCCTTGAGATGA \\
Forward & \\
Reverse & AGGTCGGTGTGAACGGATTTG \\
\hline
\end{tabular}

2X TSINGKE ${ }^{\circledR}$ MasterMix (Bejing TsingKe Biotech Co., Ltd.) in a $20 \mu \mathrm{l}$ reaction mixture containing specific primers. PCR amplification reaction was conducted as follows: $5 \mathrm{~min}$ at $94^{\circ} \mathrm{C}$, followed by 40 cycles of $30 \mathrm{sec}$ at $94^{\circ} \mathrm{C}, 30 \mathrm{sec}$ at $55^{\circ} \mathrm{C}$, and $1 \mathrm{~min}$ at $72^{\circ} \mathrm{C}$, Then $8 \mathrm{~min}$ at $72^{\circ} \mathrm{C}$. Nat1 was used as a loading control between the control MEFs and the MEFs 48-72 $\mathrm{h}$ after the transduction with the four retroviruses. The sequences of the primers used for PCR are listed in Table I.

For qPCR, total RNA was extracted from iPSCs and MEF and cDNA was synthesized from the RNA as described above. qPCR was performed using SYBR Premix Ex Taq ${ }^{\mathrm{TM}}$ (Takara Bio, Inc.) in a $10 \mu 1$ reaction mixture containing $0.4 \mu \mathrm{l}$ specific primers. Each sample was run in triplicate, and expression was normalized to the endogenous reference (GAPDH). All the amplifications were performed on a LightCycler 480 system (Roche Diagnostics), PCR amplification reaction was conducted as follows: $10 \mathrm{~min}$ at $95^{\circ} \mathrm{C}$, followed by 40 cycles of $15 \mathrm{sec}$ at $95^{\circ} \mathrm{C}$ and $1 \mathrm{~min}$ at $60^{\circ} \mathrm{C}$. and fold expression relative to the reference gene was calculated using the comparative method $2^{-\Delta \Delta C q}$ method (21). The sequences of the primers used for qPCR are listed in Table II.

Western blot analysis. Following induction of neural differentiation by a range of cytokines and RA, iPSC-derived cells were washed with cold PBS and lysed with RIPA lysis buffer (Boster Biological Technology) supplemented with a protease inhibitor cocktail (Thermo Fisher Scientific, Inc.) and phosphatase inhibitor tablets (Roche Diagnostics). The protein concentration of the supernatant was measured using BCA reagents. Equivalent amounts of protein lysates $(\sim 25 \mu \mathrm{g} / \mathrm{lane})$ were loaded on a $10 \%$ SDS-gel, resolved using SDS-PAGE and transferred to a nitrocellulose membrane (Pall Life Sciences), which was then blocked using 5\% skimmed milk in TBST 

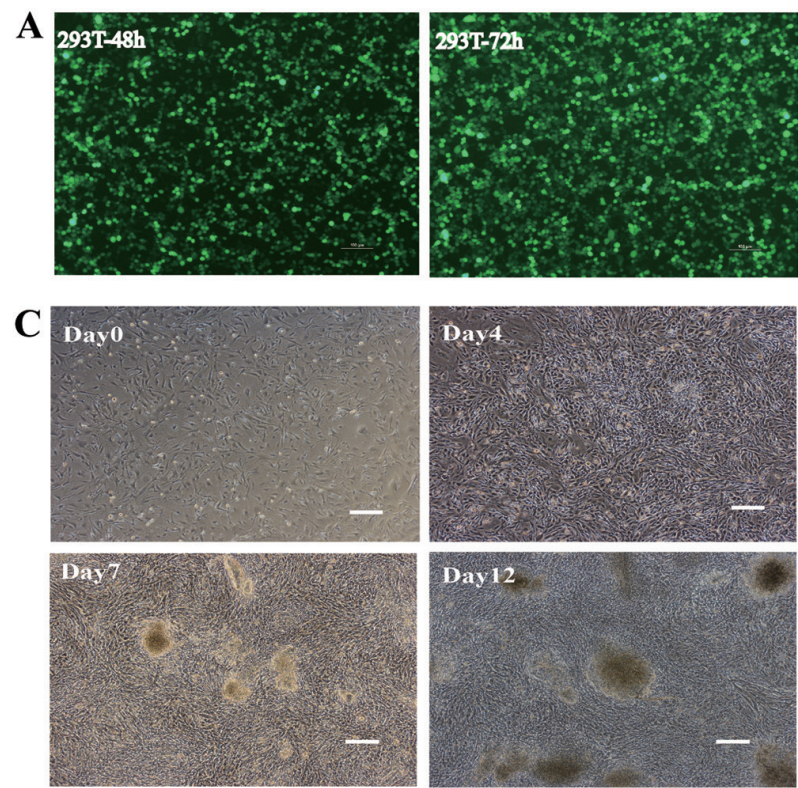
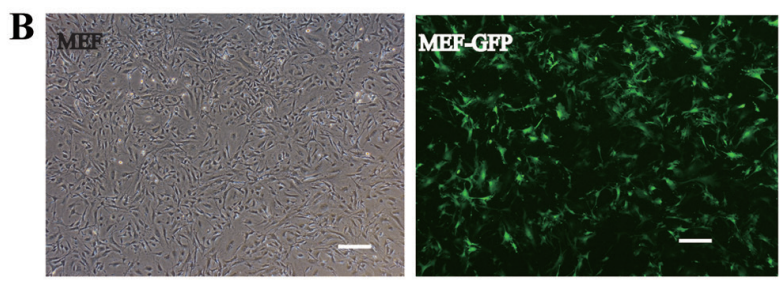

$\mathbf{D}$

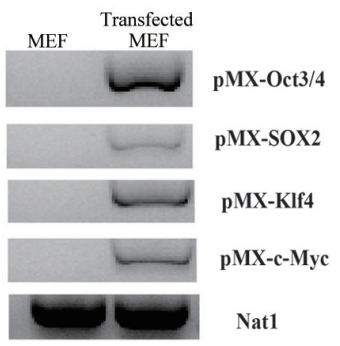

Figure 1. Evaluation of transfection efficiency of retrovirus for reprogramming MEFs. (A) GFP was observed 48 and 72 h after transfection of $293 \mathrm{~T}$ cells (B) GFP expression $72 \mathrm{~h}$ after infection of MEFs using the control pMXs-GFP plasmid. (C) Morphological changes observed during the process of reprogramming of MEFs into iPSCs. Scale bars, $100 \mu \mathrm{m}$. (D) PCR identifying expression of the transgenes Oct3/4, Sox2, c-Myc and Klf4 in control and transfected MEFs 48-72 $\mathrm{h}$ after transduction with the Oct3/4, Sox2, c-Myc and K1f4 retrovirus genes. MEF, mouse embryonic fibroblast.

(150 mM NaCl, 0.1\% Tween-20, 25 mM Tris-HCl, pH 7.6) at room temperature for $2 \mathrm{~h}$. The membranes were subsequently incubated with primary antibodies overnight at $4^{\circ} \mathrm{C}$ and washed with TBST the following day. After incubating with the secondary IRDye 680 goat anti-mouse antibody (1:5,000; Abcam; cat. no. ab216776) for $2 \mathrm{~h}$ at room temperature, signals were visualized using an Odyssey Infrared Imaging system (LI-COR Biosciences). The primary antibodies used were rabbit anti-Bmi1 $(1: 5,000$; Abcam; cat. no. ab38295) and mouse anti- $\beta$-actin (1:5,000; Sigma-Aldrich; Merck KGaA; cat. no. A5441).

Statistical analysis. Data are presented as the mean \pm the standard error of the mean of three independent repeats. Comparisons between two groups were performed using a Student's t-test (for two groups) or a one-way ANOVA followed by a Student-Newman-Keuls post-hoc test for multiple groups. $\mathrm{P}<0.05$ was considered to indicate a statistically significant difference. The data were analyzed using GraphPad Prism version 5 (GraphPad Software, Inc.).

\section{Results}

Generation and characterization of mouse iPSCs derived from MEFs. Before reprogramming, the transfection efficiency of retroviruses was evaluated. Retroviruses were generated by transfection of $80 \%$ confluent 293 T cells with the control plasmid pMXs-GFP (Fig. 1A). Retroviruses were harvested after 48 and $72 \mathrm{~h}$ post-transfection to infect the MEFs. The green signal from GFP in MEFs was visible following infection (Fig. 1B), which suggested that the cells had been successfully transfected, and that the retroviruses could be used to reprogram the MEFs into iPSCs. MEFs from ICR mice at passage 3 were used to reprogram iPSCs by retrovirally expressing Klf4, c-Myc,Sox 2 and Oct4. Colonies were visualized 7 days after transduction, and numerous large colonies were observed on day 12 (Fig. 1C). PCR analysis showed that MEFs expressed pMX-Oct3/4, pMX-Sox2, pMX-c-Myc and pMX-Klf4 genes 48-72 $\mathrm{h}$ after transfection with the respective retrovirus particles (Fig. 1D). The large colonies were screened out and passaged for culture in mouse ESC medium (Fig. 2A). Through AP staining and immunofluorescence staining analysis, the mouse iPSC colonies were shown to be strongly positive for AP. iPSCs exhibited positive staining for Oct3/4 and SSEA-1 (Fig. 2B-D). The mouse iPSCs were capable of achieving in-vitro differentiation to form EBs that were positive for $\alpha$-smooth muscle actin (mesoderm marker), $\alpha$-fetoprotein/(endoderm marker), and $\beta$ III tubulin (ectoderm marker) as shown by immunostaining (Fig. 2E and F). The endogenous pluripotency factors, including Oct3/4, Sox 2, c-Myc, Klf4 and Nanog were expressed in the reprogrammed iPSCs (Fig. 2G). These data confirmed that the reprogrammed mouse iPSCs had similar pluripotency properties to that of mouse ESCs, and that mouse iPSCs had been generated through the reprogramming of MEFs.

In-vitro neural differentiation of mouse iPSCs. After confirming the pluripotency of mouse iPSCs, they were differentiated into neuronal cells, with the aim of establishing neural stem cells (NSCs). iPSCs were first induced to form EBs, and then EBs were induced after 7 days to further form neural cells in N2B27 medium containing EGF $(10 \mu \mathrm{g} / \mathrm{ml})$ and bFGF $(10 \mu \mathrm{g} / \mathrm{ml})$. After another 7 days of adherent inducement, rosette-like structures were observed (Fig. 3A and B). Immunofluorescence analysis was performed to detect expression of neural proteins. Nestin, Vimentin and Glast were expressed in these cells, suggesting that neural cells were successfully established from mouse iPSCs (Fig. 3C).

Bmil participates in the neural differentiation of mouse $i P S C s$. During the neural differentiation of mouse iPSCs, it was found that Bmil gene expression was increased, suggesting 
A
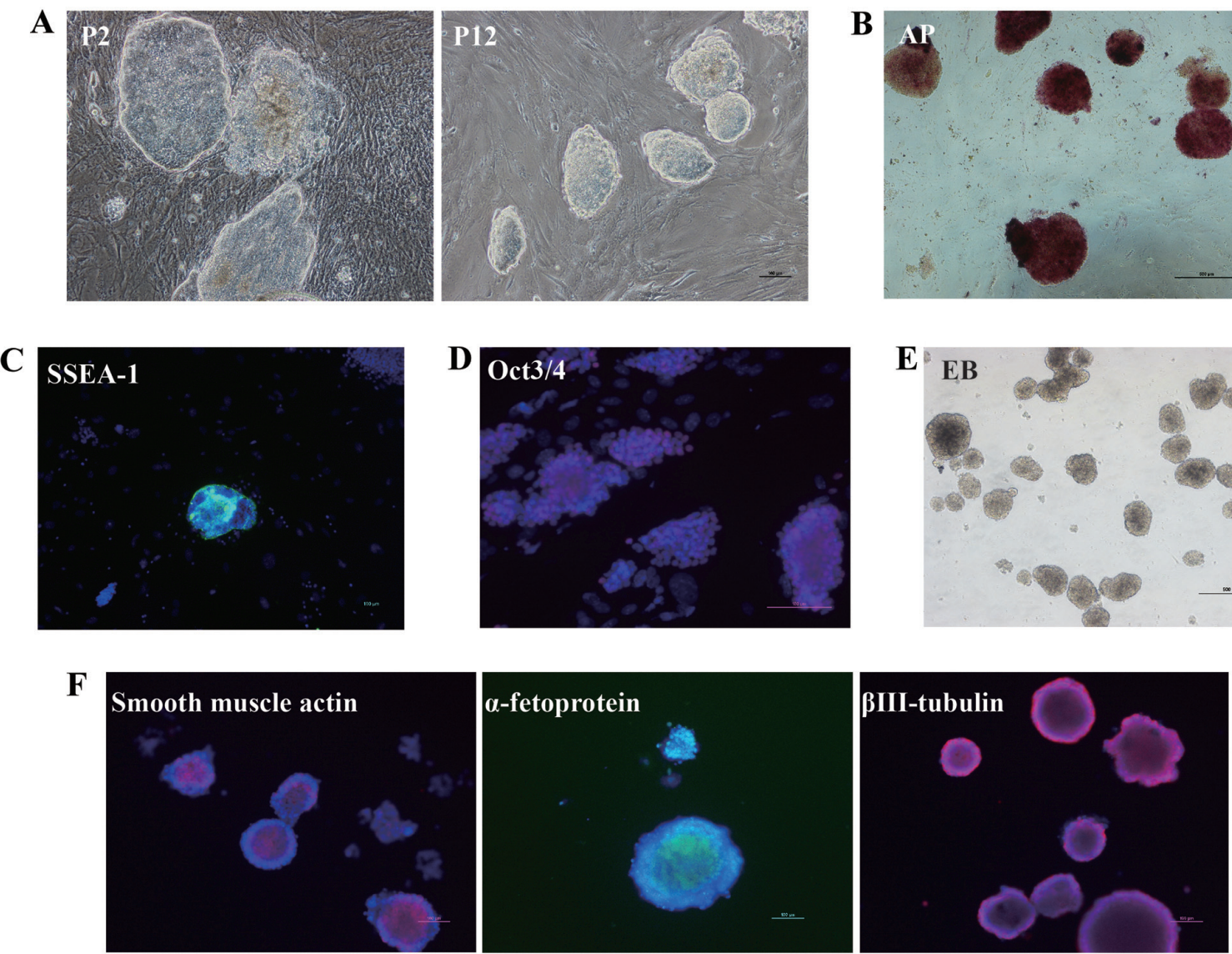

G

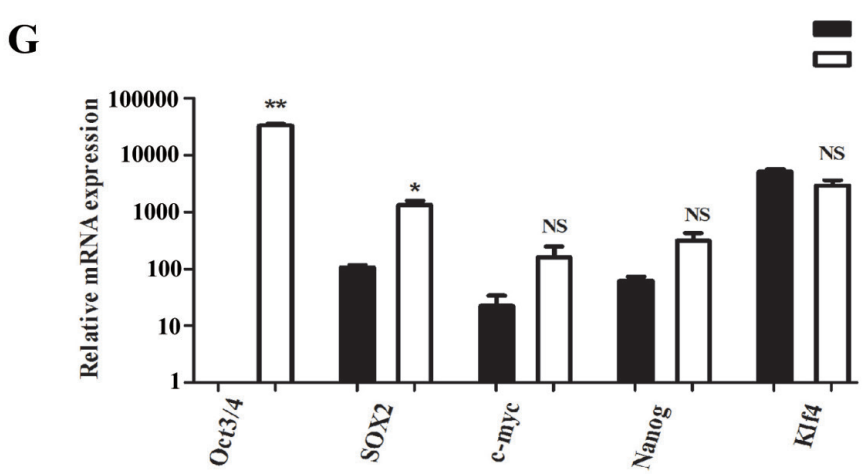

B
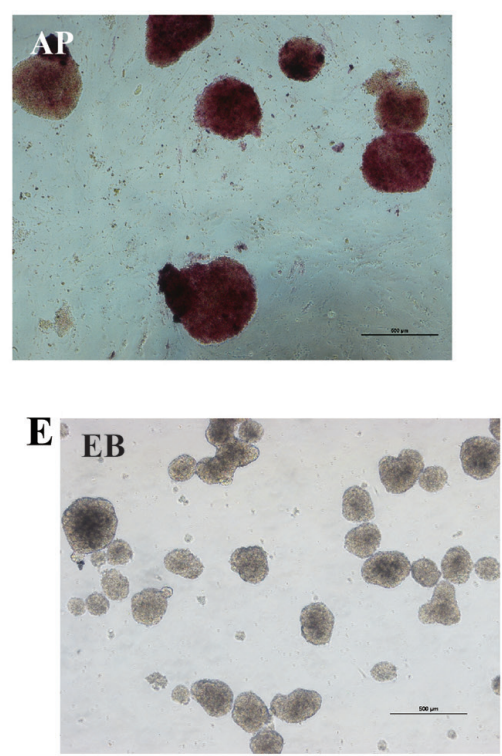
A

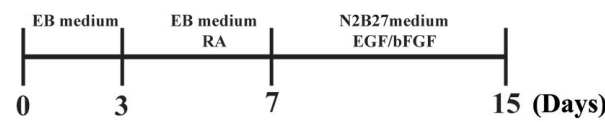

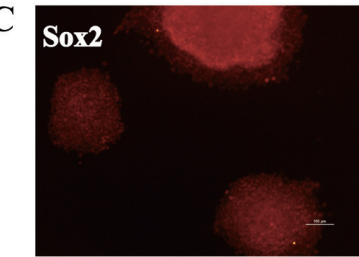
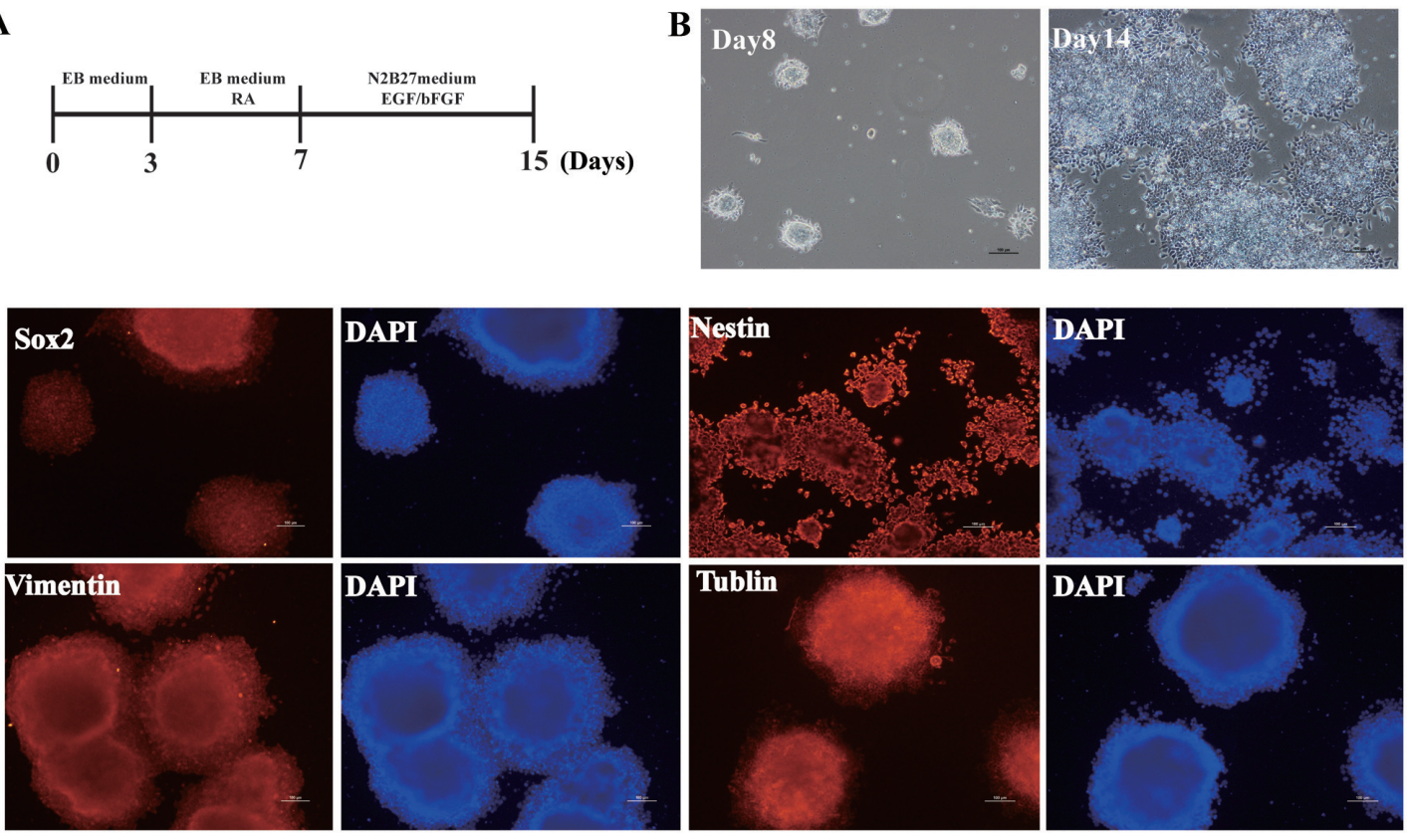

Figure 3. In vitro neural differentiation of reprogrammed mouse iPSCs. (A) Schematic representation of the neural differentiation strategy. (B) Representative bright-field microscopy showing the morphological changes during the process of neural differentiation. (C) iPSC-derived cells were immunopositive for Nestin, Sox 2, Vimentin and Tubulin. Scale bars, $100 \mu \mathrm{m}$. iPSC, induced pluripotent stem cell; EB, embryoid body; EGF, epidermal growth factor; bFGF, basic fibroblast growth factor; RA, retinoic acid.

A

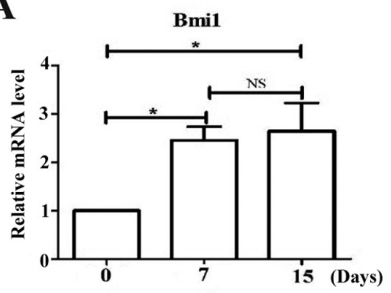

B

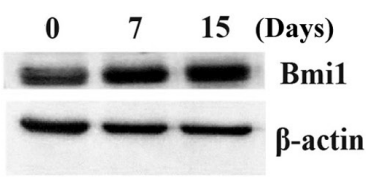

C

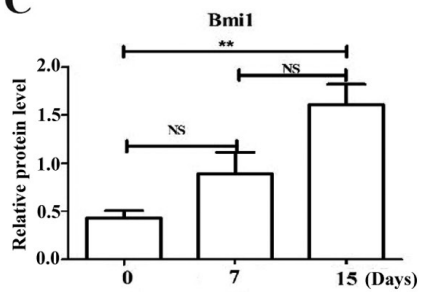

D

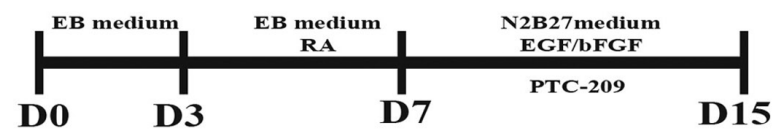

$\mathbf{E}$

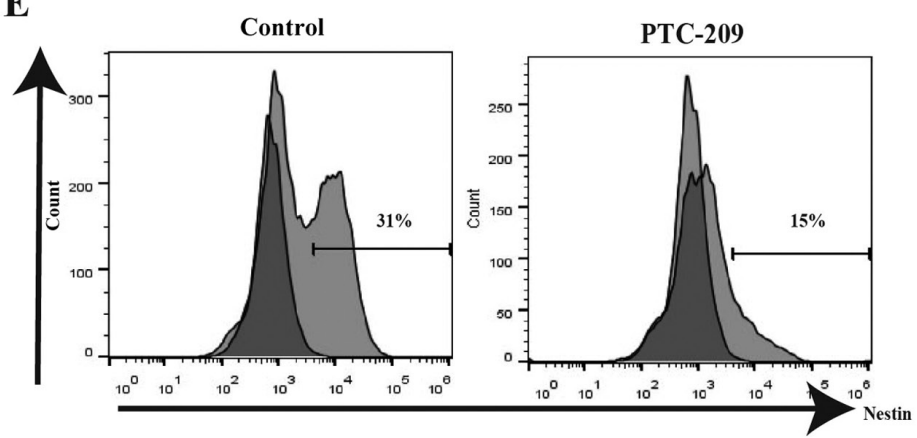

$\mathbf{F}$

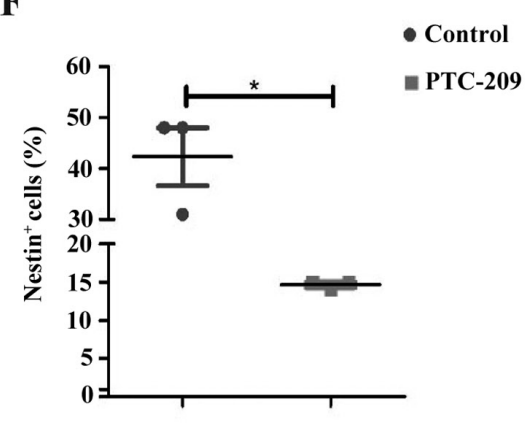

Figure 4. Bmil regulates neural differentiation of iPSCs. (A) Gene expression levels of Bmil during the neural differentiation process. (B) Protein expression levels of Bmil in the different groups. $\beta$-actin was used as the internal control. (C) Densitometry analysis of Bmil protein expression. (D) Schematic representation of the neural differentiation strategy. (E) Nestin protein expression on day 14 was measured using flow cytometry. Data are representative of three independent experiments. (F) Statistical analysis of the percentage of Nestin ${ }^{+}$cells in the presence of PTC-209 or DMSO. Data are presented as the mean \pm standard deviation. " $\mathrm{P}<0.05,{ }^{* * *} \mathrm{P}<0.01$. iPSC, induced pluripotent stem cell; EB, embryoid body; EGF, epidermal growth factor; bFGF, basic fibroblast growth factor; RA, retinoic acid.

and Oct3/4 (19). According to previous studies, a protocol for differentiation of mouse iPSCs into neural cell lineages was established, providing a platform for studying neural regulatory mechanisms in vitro, whilst also laying down a 
theoretical foundation for iPSC-based disease modeling and drug screening $(1,26,27)$.

In the present study, the procedure used to differentiate mouse iPSCs into neural cell lineages was dependent on the sequential induction at the right time intervals through the use of growth factors and small molecular compounds that serve a role in embryonic neural development in vivo and in vitro $(3,4,28,29)$. RA, EGF and bFGF were used to promote the genesis of neural cells from mouse iPSCs. Previous studies have confirmed that RA promotes neural differentiation of PSCs in EB culture, in which $0.5 \mu \mathrm{M}$ RA may have induced the generation of large numbers of neurons through the suppression of endogenous Wnt-dependent nodal signaling in a non-cell-autonomous manner $(28,30)$. EGF and bFGF are required for proliferation of neural progenitor cells (29). Nestin, Vimentin, Tubulin and Sox 2 expression are characteristic of multipotent NSCs, and were expressed in the neural differentiated cells in the present study.

Bmil is required to maintain the pool of adult stem cells, such as NSCs and HSCs $(17,18,31)$. In the present study, Bmi1 exhibited a positive regulatory role in the neural differentiation of mouse iPSCs, suggesting that overexpression of this gene may improve differentiation from mouse iPSCs to neural stem cells, and the subsequent NSC-derived cells. When the small molecule Bmil inhibitor PTC-209 was used to inhibit the neural differentiation of iPSCs, Nestin protein expression was downregulated. The dependence on Bmil for stem cell maintenance has been illustrated, where Bmil suppresses the lnk4a/ARF cell cycle inhibitory proteins (p16 and p19), whose activities are increased with postnatal time and age in culture, and are further upregulated in Bmil knockout mice when compared with wild-type mice (14). Bmil can regulate the neural differentiation of iPSCs by lnk4a/ARF cell cycle inhibitory proteins as well as the downstream signaling pathways. Thus, the specific mechanism by which Bmil regulates these processes may be worthy of further study.

In conclusion, the present study is the first to show that Bmil positively regulates neural differentiation of mouse iPSCs. The neural differentiation of iPSCs may provide a novel platform for studying neuronal development, tissue repair, regenerative medicine and disease modeling, and may also be used as a useful tool for individualized assessment of novel therapeutic compounds.

\section{Acknowledgements}

The authors would like to thank Ms. Yanwei Li (Department of Core Facilities, Zhejiang University School of Medicine) for providing technical support concerning the present study.

\section{Funding}

The present study was supported by the National Natural Science Foundation of China (grant no. 31570994).

\section{Availability of data and materials}

The datasets used and/or analyzed during the present study are available from the corresponding author on reasonable request.

\section{Authors' contributions}

QY and WS conceived and designed the experiments. WS and DL performed the experiments. WS, LZ, LL and DL were responsible for data analysis and interpretation. WS wrote the manuscript. LL and QY confirm the authenticity of all the raw data. All authors reviewed and approved the final manuscript.

\section{Ethics approval and consent to participate}

All animal experiments were performed in accordance with the guidelines described in the Institutional Animal Care Committee of Zhejiang Chinese Medical University. The present study was approved by the Laboratory Animal Management and Welfare Ethical Review Committee (approval no. ZSLL-2017-181).

\section{Patient consent for publication}

Not applicable.

\section{Competing interests}

The authors declare that they have no competing interests.

\section{References}

1. Ford E, Pearlman J, Ruan T, Manion J, Waller M, Neely GG and Caron L: Human pluripotent stem cells-based therapies for neurodegenerative diseases: Current status and challenges. Cells 9: 2517, 2020.

2. Kolagar TA, Farzaneh M, Nikkar N and Khoshnam SE: Human pluripotent stem cells in neurodegenerative diseases: Potentials, advances and limitations. Curr Stem Cell Res Ther 15: 102-110, 2020.

3. Yao XL, Liu Q, Ye CH, Li ZP, Lu XL, Li PL, Li XB and Li WQ: Neuronal differentiation potential of mouse induced pluripotent stem cells. Neuroreport 22: 689-695, 2011.

4. Aharonowiz M,Einstein O, Fainstein N,Lassmann H, Reubinoff B and Ben-Hur T: Neuroprotective effect of transplanted human embryonic stem cell-derived neural precursors in an animal model of multiple sclerosis. PLoS One 3: e3145, 2008.

5. Ben-Hur T, Idelson M, Khaner H, Pera M, Reinhartz E, Itzik A and Reubinoff BE: Transplantation of human embryonic stem cell-derived neural progenitors improves behavioral deficit in Parkinsonian rats. Stem Cells 22: 1246-1255, 2004.

6. Lee TI, Jenner RG, Boyer LA, Guenther MG, Levine SS, Kumar RM, Chevalier B, Johnstone SE, Cole MF, Isono K, et al: Control of developmental regulators by Polycomb in human embryonic stem cells. Cell 125: 301-313, 2006.

7. Du ZW and Zhang SC: Neural differentiation from embryonic stem cells: Which way? Stem Cells Dev 13: 372-381, 2004.

8. Salewski RP, Buttigieg J, Mitchell RA, van der Kooy D, Nagy A and Fehlings MG: The generation of definitive neural stem cells from PiggyBac transposon-induced pluripotent stem cells can be enhanced by induction of the NOTCH signaling pathway. Stem Cells Dev 22: 383-396, 2013.

9. Souied E, Pulido J and Staurenghi G: Autologous induced stem-cell-derived retinal cells for macular degeneration. $\mathrm{N}$ Engl J Med 377: 792, 2017.

10. Cyranoski D: Trials of embryonic stem cells to launch in China. Nature 546: 15-16, 2017

11. White N and Sakiyama-Elbert SE: Derivation of specific neural populations from pluripotent cells for understanding and treatment of spinal cord injury. Dev Dyn 248: 78-87, 2019.

12. Malgrange B, Borgs L, Grobarczyk B, Purnelle A, Ernst P, Moonen G and Nguyen L: Using human pluripotent stem cells to untangle neurodegenerative disease mechanisms. Cell Mol Life Sci 68: 635-649, 2011. 
13. Okada Y, Shimazaki T, Sobue G and Okano H: Retinoic-acidconcentration-dependent acquisition of neural cell identity during in vitro differentiation of mouse embryonic stem cells. Dev Biol 275: 124-142, 2004.

14. Ding X, Lin Q, Ensenat-Waser R, Rose-John S and Zenke M: Polycomb group protein Bmil promotes hematopoietic cell development from embryonic stem cells. Stem Cells Dev 21: 121-132, 2012.

15. He S, Iwashita T, Buchstaller J, Molofsky AV, Thomas D and Morrison SJ: Bmi-1 over-expression in neural stem/progenitor cells increases proliferation and neurogenesis in culture but has little effect on these functions in vivo. Dev Biol 328: 257-272, 2009.

16. Yadirgi G, Leinster V, Acquati S, Bhagat H, Shakhova O and Marino S: Conditional activation of Bmil expression regulates self-renewal, apoptosis, and differentiation of neural stem/progenitor cells in vitro and in vivo. Stem Cells 29: 700-712, 2011.

17. Molofsky AV, He S, Bydon M, Morrison SJ and Pardal R: Bmi-1 promotes neural stem cell self-renewal and neural development but not mouse growth and survival by repressing the p16Ink4a and p19Arf senescence pathways. Genes Dev 19: 1432-1437, 2005.

18. Fasano CA, Dimos JT, Ivanova NB, Lowry N, Lemischka IR and Temple S: shRNA knockdown of Bmi-1 reveals a critical role for p21-Rb pathway in NSC self-renewal during development. Cell Stem Cell 1: 87-99, 2007.

19. Takahashi K, Tanabe K, Ohnuki M, Narita M, Ichisaka T, Tomoda K and Yamanaka S: Induction of pluripotent stem cells from adult human fibroblasts by defined factors. Cell 131: 861-872, 2007

20. Takahashi $\mathrm{K}$ and Yamanaka S: Induction of pluripotent stem cells from mouse embryonic and adult fibroblast cultures by defined factors. Cell 126: 663-676, 2006.

21. Livak KJ and Schmittgen TD: Analysis of relative gene expression data using real-time quantitative PCR and the 2(-Delta Delta C(T)) method. Methods 25: 402-408, 2001.

22. Li L, Chao J and Shi Y: Modeling neurological diseases using iPSC-derived neural cells: iPSC modeling of neurological diseases. Cell Tissue Res 371: 143-151, 2018.
23. Deng J, Zhang Y, Xie Y, Zhang L and Tang P: Cell transplantation for spinal cord injury: Tumorigenicity of induced pluripotent stem cell-derived neural stem/progenitor cells. Stem Cells Int 2018: 5653787, 2018.

24. Czepiel M, Balasubramaniyan V, Schaafsma W, Stancic M, Mikkers H, Huisman C, Boddeke E and Copray S: Differentiation of induced pluripotent stem cells into functional oligodendrocytes. Glia 59: 882-892, 2011.

25. Onorati M, Camnasio S, Binetti M, Jung CB, Moretti A and Cattaneo E: Neuropotent self-renewing neural stem (NS) cells derived from mouse induced pluripotent stem (iPS) cells. Mol Cell Neurosci 43: 287-295, 2010.

26. Yan Y, Shin S, Jha BS, Liu Q, Sheng J, Li F, Zhan M, Davis J, Bharti K, Zeng X, et al: Efficient and rapid derivation of primitive neural stem cells and generation of brain subtype neurons from human pluripotent stem cells. Stem Cells Transl Med 2: 862-870, 2013.

27. D'Aiuto L, Zhi Y, Kumar Das D, Wilcox MR, Johnson JW, McClain L, MacDonald ML, Di Maio R, Schurdak ME, Piazza P, et al: Large-scale generation of human iPSC-derived neural stem cells/early neural progenitor cells and their neuronal differentiation. Organogenesis 10: 365-377, 2014.

28. Tonge PD and Andrews PW: Retinoic acid directs neuronal differentiation of human pluripotent stem cell lines in a non-cell-autonomous manner. Differentiation 80: 20-30, 2010.

29. Reynolds BA, Tetzlaff W and Weiss S: A multipotent EGF-responsive striatal embryonic progenitor cell produces neurons and astrocytes. J Neurosci 12: 4565-4574, 1992.

30. Engberg N, Kahn M, Petersen DR, Hansson M and Serup P Retinoic acid synthesis promotes development of neural progenitors from mouse embryonic stem cells by suppressing endogenous, Wnt-dependent nodal signaling. Stem Cells 28: 1498-1509, 2010.

31. Park IK, Qian D, Kiel M, Becker MW, Pihalja M, Weissman IL, Morrison SJ and Clarke MF: Bmi-1 is required for maintenance of adult self-renewing haematopoietic stem cells. Nature 1423: 302-305, 2003.

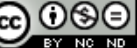

$$
\begin{aligned}
& \text { This work is licensed under a Creative Commons } \\
& \text { Attribution-NonCommercial-NoDerivatives } 4.0 \\
& \text { International (CC BY-NC-ND 4.0) License. }
\end{aligned}
$$

